\title{
Impressões e Sentimentos de Gestantes em Relação à Ultra-Sonografia Obstétrica no Contexto de Normalidade Fetal
}

\author{
Impressions and Feelings of Pregnant Women Concerning Obstetric \\ Ultrasound in the Context of Fetal Normality
}

\author{
Aline Grill Gomes \& Cesar Augusto Piccinini* \\ Universidade Federal do Rio Grande do Sul, Porto Alegre, Brasil
}

\begin{abstract}
Resumo
O objetivo desta pesquisa foi investigar as impressões e sentimentos das gestantes sobre a ultra-sonografia obstétrica, no contexto de normalidade fetal. Participaram do estudo 11 gestantes primíparas, com idades entre 18 e 35 anos e idades gestacional entre 11 e 24 semanas, que estavam sendo submetidas pela primeira vez à ultrasonografia. Elas responderam a uma entrevista semi-estruturada, antes, logo depois e três semanas depois do exame. Análise de conteúdo qualitativa das entrevistas revelou a satisfação e a intensidade vivenciadas no exame; a sua importância ao permitir conhecer o bebê antes do nascimento; por promover um sentimento de concretização da gravidez e do bebê; e, por informar sobre a saúde do bebê, possibilitando intervenções precoces. Repercussões do exame envolveram, ainda, maior aproximação e cuidado dos familiares para com a gestante. A ultra-sonografia parece ser um momento notório no transcorrer da gravidez, merecendo atenção dos familiares e, especialmente, dos profissionais de saúde envolvidos.

Palavras-chave: Ultra-sonografia; impressões e sentimentos; gestantes; normalidade fetal.
\end{abstract}

\begin{abstract}
The aim of this study was to investigate the impressions and feelings of pregnant women concerning obstetric ultrasound in the context of fetal normality. Eleven primiparous pregnant women, ages 18 to 35 and with 11 to 24 weeks of gestation, who were undergoing ultrasound examinations for the first time, took part in the study. Semi-structured interviews were conducted before, during and three weeks after the examination. Qualitative content analysis of the interviews revealed that the examination rendered an experience of satisfaction and intensity; is important as it allows for the baby to be known before birth; promotes the feeling of concreteness of both the pregnancy and the baby; informs about the baby's health, enabling early interventions. Repercussions of the examination also involved greater contact and care of the pregnant women from relatives. Obstetric ultrasound seems to be a remarkable moment during pregnancy, deserving attention from relatives and, especially, from the health professionals involved.

Keywords: Ultrasound; impressions and feelings; pregnant women; fetal normality.
\end{abstract}

A ultra-sonografia obstétrica, além de determinar características gerais do feto e identificar gestações múltiplas, é também capaz de dirimir dúvidas quanto à saúde e o bemestar fetal (Grebedenik, 1990; Isfer, 1997; Magalhães, 2001). Pode-se dizer, então, que a partir do exame ultrasonográfico introduziu-se uma nova forma de contato com o bebê, possibilitando à gestante visualizá-lo e conhecê-lo antes de seu nascimento (Fonseca, Magalhães, Papich, Dias, \& Schimidt, 2000; Klaus \& Kennel, 1992).

Assim, a ultra-sonografia pode se constituir em um momento de emoções bastante intensas e importantes para a gestante e para a relação com o bebê. Estudos que observaram o comportamento das gestantes durante o exame ecográfico revelaram que elas permaneceram muito atentas às imagens apresentadas na tela do aparelho, e suas

\footnotetext{
* Endereço para correspondência: Universidade Federal do Rio Grande do Sul, Instituto de Psicologia, Departamento de Psicologia do Desenvolvimento e da Personalidade, Rua Ramiro Barcelos, 2600/111, Bom Fim, Porto Alegre, RS, 90035003. Fone: (51) 33165246; Fax: (51) 33165473. E-mail: piccinini@portoweb.com.br
}

expressões faciais foram de muita seriedade e "absorção" (Milne \& Rich, 1981). O que acontecia no ambiente não era capaz de lhes chamar atenção, elas mantinham-se fixas às imagens.

Isto estaria associado à sobrecarga emocional provocada pelo exame, isto é, a rapidez do encontro mãe-feto através das imagens apresentadas na tela causaria uma vivência de extrema intensidade (Caron, Fonseca \& Kompinsky, 2000). Diversos elementos aparecem de uma só vez, sobrecarregando o aparelho mental, e fazendo com que conteúdos inconscientes possam vir à tona. Assim, o ambiente do exame ecográfico tem um impacto bastante importante em ambos os pais, isto é, nunca é algo que produz indiferença; "pode gerar amor ou ódio, mas sempre algum sentimento é acionado pelas imagens que aparecem na tela do aparelho de ultra-sonografia” (Fonseca et al., 2000, p. 113).

A ultra-sonografia tende a ser acompanhada de alto grau de ansiedade para as gestantes, o que é evidenciado pelas suas expressões faciais, gestos e verbalizações (Milne \& Rich, 1981). É que é como se ocorresse uma espécie de 
"teste da verdade" (Raphael-Leff, 1991) ou "controle/selo de qualidade” (Quayle, 1997b), a partir do qual o casal é avaliado em sua capacidade procriativa de forma bastante direta. Todos os aspectos deles que estavam projetados no bebê são, agora, alvo de investigação; o bebê ao ser examinado está trazendo com ele o "eu” parental (Quayle, Isfer \& Zugaib, 1991; Quayle, Neder, Mihaydaira \& Zugaib, 1996).

Desta maneira, percebe-se também que a ultrasonografia disponibiliza um acesso da gestante ao seu próprio corpo, a si mesma como mulher e mãe e, é claro, como enfatiza Piontelli (2000), à forma e o comportamento de seu filho. $\mathrm{O}$ encontro com o bebê real é parcialmente antecipado (Caron, 2000). Com os dados concretos que o exame revela a respeito do bebê, os pais podem, desde já, confrontar o bebê imaginário com o bebê real. É notável que este impacto é diferente para cada mãe e o potencial de cada uma delas de lidar com estas expectativas e frustrações interferirá na relação que se estabelece com o bebê, o que torna importante que possamos compreender a visão das gestantes sobre a ultrasonografia e sobre suas implicações.

Concernente aos efeitos da ultra-sonografia para a relação materno-fetal, a maioria dos estudos salienta a ocorrência de repercussões positivas, como a concretização da existência do bebê e um maior apoderamento do papel de mãe (Baillie, Mason \& Hewison, 1997; Caccia, Johnson, Robinson \& Barna, 1991; Fletcher \& Evans, 1983; Garrett \& Carlton, s.d.; Kohn, Nelson \& Weiner, 1980; Raphael-Leff, 1997; Sioda, 1984). Porém, outros autores enfatizam aspectos negativos, evidenciando, em especial, que a ultra-sonografia traz à tona uma realidade muito precoce, fazendo com que a imagem real do feto destrua as fantasias maternas e a gestante se sinta invadida, prejudicando, então, o processo de representação psíquica da mãe sobre o bebê (Courvoisier, 1985; Fletcher \& Evans, 1983; Soulé, 1987). A literatura apresenta, também, um grupo de pesquisas que utilizaram uma escala para medir o apego materno-fetal antes e logo depois do exame ecográfico e que não encontrou quaisquer efeitos da ultra-sonografia no apego materno-fetal (Heidrich
\& Cranley, 1989; Kemp \& Page, 1987). Sabe-se, ainda, que as gestantes, mesmo passados dias do exame, seguem elaborando as imagens reais da ultra-sonografia, na tentativa de construir uma imagem mental de seu filho (Milne \& Rich, 1981). No entanto, grande parte dos estudos que tratam do tema investiga as repercussões da ultra-sonografia somente no momento imediato após o exame. Assim, o presente estudo buscou investigar as impressões e sentimentos das gestantes sobre a ultra-sonografia obstétrica no contexto de normalidade fetal em três momentos: antes, logo depois e três semanas depois do exame.

\section{Método}

\section{Participantes}

Participaram deste estudo 11 gestantes em situação de normalidade fetal. As gestantes eram primíparas, sendo que nove eram primigestas e duas já tinham tido pelo menos um aborto espontâneo. A Tabela 1 apresenta as características demográficas das participantes. As gestantes tinham idade entre 18 e 35 anos $(M=23,45 ; D P=5,56)$, e eram de nível sócio-econômico baixo a médio, com base na sua escolaridade ( $M=9$ anos estudados; $D P=2,53$ anos) e profissão. A idade gestacional variou de 11 a 24 semanas de gestação $(M=15,09 ; D P=4,44)$ e todas elas estavam sendo submetidas pela primeira vez na vida à ultra-sonografia obstétrica. Quanto a atividade profissional, quatro gestantes exerciam atividades no lar, quatro trabalhavam com serviços gerais, uma era estudante, e duas tinham atividades técnicas. Algumas participantes tinham primeiro grau incompleto $(n=2)$, ou completo $(n=3)$ e as demais, segundo grau completo $(n=4)$ ou incompleto $(n=2)$. Todas mantinham relacionamento estável com o pai do bebê.

As participantes foram recrutadas entre as que estavam sendo submetidas à ultra-sonografia obstétrica no Serviço de Medicina Fetal do Hospital de Clínicas de Porto Alegre, durante o período de julho a dezembro de 2002, sob a aprovação do comitê de ética desta instituição. Eram convidadas

Tabela 1

Dados Demográficos das Gestantes

\begin{tabular}{|c|c|c|c|c|c|c|}
\hline Gestante & Idade & $\begin{array}{c}\text { Idade } \\
\text { Gestacional } \\
\text { (semanas) }\end{array}$ & Paridade & Escolaridade & Ocupação & $\begin{array}{c}\text { Situação } \\
\text { Marital } \\
\text { (c/ pai do bebê })\end{array}$ \\
\hline G1 & 23 & 11 & Primípara* & $1^{\circ} \mathrm{G}$ incompleto & Empregada doméstica & Mora junto há $5 \mathrm{a}$ \\
\hline G2 & 20 & 13 & Primípara*** & $2^{\circ} \mathrm{G}$ completo & Sem atividade & Mora junto há 3m \\
\hline G3 & 22 & 11 & Primigesta & $2^{\circ} \mathrm{G}$ completo & Sem atividade & Namora há $1 \mathrm{a}$ e $2 \mathrm{~m}$ \\
\hline G4 & 18 & 20 & Primigesta & $2^{\circ} \mathrm{G}$ incompleto & Estudante & Mora junto há $2^{\text {a }}$ \\
\hline G5 & 21 & 24 & Primigesta & $2^{\circ} \mathrm{G}$ incompleto & Serviços gerais & Noiva há $4^{\mathrm{a}}$ \\
\hline G6 & 26 & 13 & Primigesta & $1^{\circ} \mathrm{G}$ incompleto & Serviços gerais & Casada há $5^{\text {a }}$ \\
\hline G7 & 33 & 20 & Primigesta & $2^{\circ} \mathrm{G}$ completo & Aux. administrativa & Mora junto há $3^{\text {a }}$ \\
\hline G8 & 19 & 11 & Primigesta & $1^{\circ} \mathrm{G}$ completo & Sem atividade & Namora há 3a e 3m \\
\hline G9 & 18 & 15 & Primigesta & $2^{\circ} \mathrm{G}$ completo & Sem atividade & Namora há 1 a e $2 \mathrm{~m}$ \\
\hline G10 & 24 & 12 & Primigesta & $2^{\circ} \mathrm{G}$ incompleto & Estudante/Camareira & Casada há 6a e 6m \\
\hline G11 & 34 & 13 & Primigesta & $3^{\circ} \mathrm{G}$ incompleto & Técnica enfermagem & Mora junto há 5 a \\
\hline
\end{tabular}

Notas. * Com um aborto espontâneo; ** com dois abortos espontâneos. 
a participar do estudo todas as gestantes que preenchiam aos critérios de inclusão da amostra (primíparas, 18 a 35 anos, idade gestacional a partir de 11 semanas, e nunca terem sido submetidas ao exame ultra-sonográfico na vida) e estavam realizando o exame nos dias em que a pesquisadora estava presente no hospital.

\section{Delineamento e Procedimento}

Foi utilizado um delineamento de estudo de caso coletivo (Stake, 1994), visando investigar as impressões e sentimentos das gestantes sobre a ultra-sonografia antes, logo depois e três semanas depois da realização do exame. Segundo o autor, este delineamento propicia compreender em profundidade um mesmo fenômeno a partir da análise de mais de um caso.

Antes da entrada das gestantes para a sala de exame, elas foram solicitadas pela pesquisadora a passar em uma ante-sala, onde foram convidadas a participar do estudo. De todas estas, nenhuma recusou o convite. O Consentimento Livre e Esclarecido (Grupo de Interação Social, Desenvolvimento e Psicopatologia [GIDEP], 1998a) foi, então, assinado e a Ficha de dados demográficos (GIDEP, 1998b) preenchida pela pesquisadora, visando obter algumas características demográficas, tais como: sexo, idade, status social, estado civil, escolaridade, profissão e endereço. As gestantes foram, então, solicitadas a responder a Entrevista sobre a história obstétrica da gestante (Gomes \& Donelli, 2001) ${ }^{1}$, que buscou dados da história obstétrica da gestante, tais como: paridade, história pregressa de saúde materna e fetal, intercorrências e condições clínicas gerais. Dados desta entrevista foram usados para verificar as gestantes que atendiam aos critérios de inclusão do presente estudo. Esta entrevista envolveu perguntas objetivas, cujas respostas foram preenchidas pela pesquisadora. Responderam também à Entrevista sobre a ultra-sonografia obstétrica e a relação materno-fetal (Gomes \& Piccinini, 2001)², que examinou as

\footnotetext{
${ }^{1}$ Gomes, A., \& Donelli, T. (2001). Entrevista de história obstétrica da gestante. Porto Alegre, RS: Universidade Federal do Rio Grande do Sul, Instituto de Psicologia. Manuscrito não publicado. O roteiro da entrevista investigava: Semanas de gestação, DUM, data provável do parto, condições de saúde durante a gravidez, condições de saúde anteriores à gravidez, número de gestações anteriores, abortos anteriores (espontâneos e provocados), ultra-sonografia obstétrica anteriores e planejamento da gravidez.

${ }^{2}$ Gomes, A., \& Piccinini, C. (2001). Entrevista sobre a ultra-sonografia obstétrica e a relação materno-fetal. Porto Alegre, RS: Universidade Federal do Rio Grande do Sul, Instituto de Psicologia. Manuscrito não publicado. Destaca-se a seguir o roteiro da entrevista, com as principais questões consideradas no presente estudo. Como esta entrevista foi realizada em três momentos: antes, logo em seguida e três semanas após o exame, foram feitas algumas adequações no roteiro para se adaptar ao momento de sua realização. Antes do exame foram abordadas as expectativas sobre o exame, as impressões e sentimentos sobre o bebê, a relação mãe-bebê e os sentimentos maternos. (Eu gostaria que você me falasse um pouco de como você está se sentindo em relação ao bebê e ao exame que você vai fazer agora?); Logo em seguida do exame, foram investigadas as impressões e sentimentos diante da experiência da ultra-sonografia, isto é, das imagens e informações oferecidas no exame (Eu gostaria que você me falasse um pouco da ultra-sonografia que você acabou de fazer; Eu gostaria que você me falasse do que você viu durante a ultra-sonografia), impressões e sentimentos sobre o bebê depois do exame (Eu gostaria que você me falasse um pouco do que você viu do bebê), impressões e sentimentos sobre a conduta do médico no exame (E o médico, o que você achou dele durante a ultra-sonografia?), sentimentos e contribuições decorrentes da experiência da ultra-sonografia (Como você está se sentindo agora após ter feito a ultra-sonografia?); Três semanas depois do exame foram investigadas as principais lembranças e impacto do exame na sua rotina (Eu gostaria que você me falasse um pouco da ultra-sonografia que você realizou
}

expectativas, impressões e os sentimentos das gestantes em relação à ultra-sonografia, e suas implicações na relação mãe-feto. Esta entrevista foi gravada em áudio e posteriormente transcrita para análise dos dados.

Em seguida, a pesquisadora acompanhou as gestantes para a sala onde foi realizado o exame ultra-sonográfico. As ultra-sonografias tiveram a duração de 15 a 30 minutos e foram realizadas por médicos ginecologistas e obstetras ou radiologistas, com especialização em ultra-sonografia fetal. Todas as ultra-sonografias foram solicitadas como procedimentos de rotina do pré-natal. O equipamento utilizado para o exame foi um Aloka SSD - 1700, que reproduz uma imagem dinâmica em duas dimensões. A pesquisadora acompanhou todo o procedimento. Após o término da ultrasonografia, as gestantes foram encaminhadas a uma outra sala onde foi realizada novamente a Entrevista sobre a ultrasonografia obstétrica e a relação materno-fetal.

Três semanas após a ultra-sonografia, as gestantes retornaram ao hospital mediante combinação com a pesquisadora e independente de quaisquer consultas ou procedimentos médicos. Nesta ocasião, foram solicitadas a responder novamente à Entrevista sobre a ultra-sonografia obstétrica e a relação materno-fetal. $\mathrm{O}$ intervalo de três semanas para este contato foi escolhido para permitir às gestantes um período de reflexão em relação à ultra-sonografia. Não foi considerado um intervalo de tempo maior, tendo em vista que esta entrevista deveria ser realizada antes de qualquer outro procedimento médico e algumas gestantes, dependendo da sua idade gestacional, são logo encaminhadas para novos exames.

\section{Análise dos Dados}

Análise de Conteúdo Qualitativa (Laville \& Dione, 1999) foi utilizada para se investigar as impressões e sentimentos das gestantes em relação à ultra-sonografia antes e depois do exame. Para tanto, foram analisados os relatos das gestantes à entrevista sobre a ultra-sonografia e se criou uma estrutura de três categorias, com base nos próprios relatos, denominadas: Expectativas antes do exame, Impressões e sentimentos durante e logo após o exame, e Impressões e sentimentos semanas depois do exame.

Dentro de cada uma destas categorias foram criadas também sub-categorias, como será visto abaixo. Para fins de análise, dois codificadores foram utilizados para a identificação das categorias, subcategorias e análise das entrevistas. Eventuais discordâncias na codificação eram dirimidas através de discussão e, quando necessário, contou-se com a apreciação de um juiz. É importante salientar que o critério para a inclusão das verbalizações nos momentos citados (antes, logo após ou três semanas depois do exame) baseou-se

\footnotetext{
há três semanas), impressões e sentimentos sobre o bebê, sobre a relação mãe-bebê e sobre os sentimentos maternos (Eu gostaria que você me falasse como está o bebêe). Para o presente artigo, não foram consideradas, em nenhum destes três momentos, as questões sobre as implicações da ultra-sonografia para a relação materno-fetal. Esse tema está apresentado em outro estudo encaminhado para publicação pelos mesmos autores, intitulado A ultra-sonografia obstétrica e suas implicações na relação materno-fetal em situações de normalidade fetal.
} 
na referência das próprias gestantes ao momento que tinham sentido e/ou pensado determinado conteúdo e não necessariamente ao momento cronológico em que foram coletados os dados.

\section{Resultados}

Apresenta-se, a seguir, os resultados desta análise, com breve descrição de cada categoria temática, exemplificando-as com trechos de relatos das próprias gestantes $^{3}$. Por fim, ao final da análise do eixo principal, apresenta-se uma discussão dos principais aspectos analisados, com base na literatura e experiência profissional (acadêmica e clínica) da autora.

\section{Expectativas Antes do Exame}

As gestantes referiram a ultra-sonografia como uma possibilidade de obter esclarecimentos sobre características gerais do bebê e do seu estado de saúde "Eu acho que é pra isso, pra ver se ele [nenê] tá perfeito, se tá bem" ${ }^{\text {. A }}$ As expectativas envolveram também os resultados do exame, o que se manifestou desde um desejo de que tudo estivesse bem " $E u$ espero que esteja tudo bem, muito bem?'; “Espero que não aconteça nada de errado"; até medo de um diagnóstico indesejado "Eu só achei assim, pensei que ia dar alguma coisa errada assim”. O procedimento em si gerou, ainda, preocupações nas gestantes que acreditavam que não compreenderiam e/ou não enxergariam as imagens com clareza "Eu sei que não vai dar pra ver muita coisa”, além de algumas terem ficado receosas com a possibilidade de que o exame lhes causasse dor.

\section{Impressões e Sentimentos Durante e Logo Após o Exame}

As gestantes descreveram o exame associando-o tanto a vivências positivas, com destaque para as sensações de satisfação e felicidade ao ver as imagens do bebê no monitor "Eu to super feliz . . e é tão bom, é gostoso ver!"; e as de alívio/ tranqüilidade ao receberem bons resultados sobre o estado de saúde do bebê "Daí eu fiquei descansada. Daí eu respirei mais, mais leve, porque eu não tava respirando”; até vivências mais negativas, como o nervosismo descrito por algumas gestantes por não saberem como seria o procedimento "Eu fiquei um pouco nervosa ... porque eu não sabia, né como ia ser ... nervosa pelo exame ... ah, como é que era o exame, se doía, eu tinha medo de fazer".

O que pareceu comum a quase todas as manifestações foi o fato de a ultra-sonografia ter sido sentida pelas gestantes como uma experiência bastante intensa e única na medida que lhes provocou reações e pensamentos bem particulares nunca antes vivenciados "É um momento único, não tem coisa

\footnotetext{
${ }^{3} \mathrm{Na}$ dissertação de mestrado na qual se baseou este trabalho são apresentados inúmeros outros exemplos das falas das gestantes, os quais não foram incluídos no presente artigo por falta de espaço. Gomes, A. (2003). A ultra-sonografia obstétrica e a relação materno-fetal: Impressões e sentimentos de gestantes com e sem diagnóstico de anormalidade fetal. Dissertação de Mestrado não-publicada, Instituto de Psicologia, Universidade Federal do Rio Grande do Sul, Porto Alegre, RS.

${ }^{4}$ A fala de uma mesma gestante não foi utilizada para exemplificar uma mesma sub-categoria.
}

igual”. Foram referidos pelas gestantes sentimentos de emoção ao enxergar o bebê "Quando a gente olha a imagem do bebê, é muito emocionante, né, tu não acredita que aquilo possa tá, aquela pessoinha tá dentro de ti”, além do desejo em externalizar essa emoção "Vontade de chorar, só o que eu senti, vontade de chorar. Fiquei emocionada ... assim, sabe rir e chorar". Outras expressaram a intensidade da experiência ao referirem que durante a realização do exame lembraram de situações importantes do passado, experenciando uma revivência de experiências anteriores "Eu só achei, pensei que ia dar alguma coisa errada assim ... porque eu já tinha perdido outro né”.

A carga emocional do momento do exame e das imagens do bebê ali mostradas provocou também sentimentos mais ligados a uma condição de paralização, a qual se fez presente no discurso das gestantes relacionada tanto a um estado emocional de choque e/ou confusão "Porque eu tô assim meio em estado de choque, de repente até agora na segunda eu até consiga perguntar mais", como à dificuldade de explicar com palavras o que foi sentido durante a realização da ultrasonografia "É difícil ... ah meu deus, é estranho, não tem palavra ... não dá para explicar, porque é uma coisa fantástica, fantástica”, e por fim à percepção das gestantes de que seus pensamentos ficaram bloqueados durante o exame "Eu não pensei né, não consegui pensar assim, parar e pensar".

Foi relatado o desejo pelas participantes em compartilhar com outras pessoas, em especial o companheiro, a experiência do exame e os sentimentos e vivências decorrentes "Eu atépensei que pena que o Jandir ${ }^{5}$ não veio junto né ... queria que ele tivesse visto também”. As gestantes revelaram muitos de seus sentimentos em relação ao exame quando atribuíram sua importância a algumas de suas funções, desde a concretização da realidade da gravidez e do bebê "Eu não tinha certeza, às vezes eu pensava assim 'será que eu to grávida?' Agora eu tenho certeza absoluta que ele está aqui dentro de mim, muito bom!", como a possibilidade de ter um contato mais visual com o bebê, permitindo que elas possam vê-lo e conhecê-lo, e serem informadas sobre seu estado de saúde, inclusive para possibilitar intervenções precoces diante de um diagnóstico indesejado "Porque eu acho que se não tiver bem, tu tem a chance de poder tratar, de ajudar o nenê para que quando ele nasça ele não nasça com sofrimento".

Um sentimento bastante verbalizado pelas gestantes foi o de surpresa pelo fato de terem compreendido e/ou enxergado as imagens com qualidade, o que pode ser exemplificado em relatos como: "Eu levei um susto, porque eu achava que não ia ver, porque eu não conseguia prestar atenção na tela”.

\section{Impressões e Sentimentos Semanas Depois do Exame}

Três semanas após o exame foram descritas vivências muito positivas envolvendo tanto a continuidade dos sentimentos de felicidade e segurança experimentados na situação/contex to do exame "Com certeza, eu tô mais segura, eu tô

\footnotetext{
${ }^{5}$ A fim de proteger a identidade dos participantes, os nomes próprios utilizados no decorrer do texto são fictícios.
} 
mais feliz, eu tô tentando fazer as coisas direitinho pra que tudo saia certo", como dos sentimentos de tranqüilidade "Eu tô melhor, tô mais tranqüila" diante dos resultados satisfatórios do exame e das condições de saúde do bebê.

A intensidade da experiência da ultra-sonografia, mesmo após passadas três semanas, permaneceu evidente nas verbalizações das gestantes, principalmente as que referiram ainda uma condição de paralização diante do que foi vivido "Eu tô meio assim em estado de choque até agora". $\mathrm{Na}$ verdade, a vivência do exame como um todo apareceu ainda muito atual para as gestantes, que disseram que tinham, até o momento, todas as imagens muito presentes em sua memória "A imagem tá na minha cabeça, não consegui esquecer nada”.

O que parece ter se modificado com o passar das semanas, diz respeito à familiaridade em relação à situação de ultra-sonografia, na medida que as gestantes, já demonstravam se sentir mais apropriadas do exame "Na próxima vez eu vou fazer ele me mostrar muito mais ... não perguntei nada, de tão nervosa, agora a próxima vez eu vou perguntar".

Esse intervalo de tempo transcorrido desde a realização do exame fez, também, com que as gestantes identificassem que a ultra-sonografia lhe serviu como um estímulo para imaginar mais sobre o bebê "Depois eu fiquei pensando qual será o tamanho dele? Qual será o peso dele? Aí eu vou nas revistas e procuro tudo né, fico lendo o tempo todo".

Os sentimentos das gestantes ligados à importância de algumas funções da ultra-sonografia foram novamente citados, sendo que a concretização da gestação e do bebê teve maior ênfase "Agora eu to acreditando que ele tá dentro de mim, antes eu não tava”. Uma nova função referida foi a de que o exame, na ocorrência de um diagnóstico de anormalidade, poderia preparar emocionalmente as gestantes para enfrentar uma realidade diferente da que estavam imaginando "Que é pra mim ficar preparada assim se tiver alguma coisa de errado, daípra mim saber já”.

Passadas três semanas da realização do exame, as gestantes manifestaram seus sentimentos, ligando-os às repercussões da ultra-sonografia já percebidas em si próprias e/ ou em suas relações interpessoais. As implicações variaram, então, desde mudanças em nível individual, que as gestantes perceberam nelas próprias após a realização do exame, até mudanças em relação a outras pessoas "Só que agora eu me encorajei e falei pra ele [pai da gestante] cheguei em casa e mostrei a ecografia", como o companheiro "Porque depois da ecografia ele ficou mais bobo ainda"; e/ou familiares "Minha mãe já tava feliz, agora ficou mais ainda!". Também foram relatadas mudanças nas suas relações interpessoais, como o aumento de cuidados dos outros em relação a si e ao bebê "Ah depois que eu falei pra ele né do nenezinho estar tudo bem ... E aí ele tem esse cuidado comigo, pra mim não fazer muito esforço, essa coisa assim", uma maior aproximação na sua relação com o companheiro "Acho que a gente ficou mais unido" e com alguns familiares "A minha mãe também ta mais apegada a mim". Por fim, a ocorrência de reconciliações familiares também foi mencionada "Daí acho que ele [pai da gestante] gostou também ... aí eu disse: olha as coisas da tua neta, daí acho que quebrou um pouco o coração, agora ta bem melhor".

\section{Discussão}

A análise dos relatos das gestantes revelou que a ultrasonografia despertou, mesmo antes de sua realização, diversas expectativas, que indicam o intenso impacto emocional que o exame já estava causando no psiquismo das gestantes. Após o procedimento e inclusive três semanas mais tarde, os sentimentos relatados também traduzem a intensidade da experiência e suas diversas implicações.

No que concerne às expectativas antes do exame, as gestantes revelaram o desejo de que a ultra-sonografia pudesse lhes trazer esclarecimentos sobre o bebê demonstrando, desta forma, uma necessidade de elas saberem o que de fato estava ocorrendo dentro de seus corpos, ou seja, como estavam as condições do bebê, como ele era e como vivia. Para sustentarmos as razões de tal necessidade, podemos pensar nas possíveis representações do bebê para a gestante. A relação da mãe com o bebê já começa no período prénatal e é necessário que o bebê já tenha sido reconhecido como um ser dono de uma identidade própria para que a interação seja estabelecida (Stainton, 1985). Esse processo de constituição de identidade se constrói para os pais através das informações obtidas sobre o bebê, como sexo, tamanho e condições de saúde, o que explica em parte a necessidade das gestantes de serem esclarecidas, através da ultra-sonografia, sobre as características gerais do bebê. Diante de tais informações, o bebê pode ser representado pela mãe como sendo um ser mais separado dela, com identidade e autonomia.

Porém, o bebê pode assumir um outro tipo de representação no universo materno, a qual envolve um estado mais indiferenciado entre quem é a mãe e quem é o bebê, como relatado por uma das gestantes "Olhar, ver como é que tá ... porque a gente não sabe como é que tá dentro da gente”. Aqui, o bebê ainda é visto pela gestante como muito misturado consigo, significando, inclusive, uma parte sua, ou como refere Ramona-Thieme (1995), uma extensão sua. Saber sobre o bebê, neste caso, pode representar para a mãe saber sobre ela mesma. A mãe deseja conhecer o seu "produto" e enxergar o que é "isso" que tem dentro dela. E "isso", nesse momento, é representado pelo bebê. É como se o bebê, durante o seu desenvolvimento, fosse servindo também como um espelho para a mãe, revelando para ela a natureza do seu interior.

O papel exercido pela ultra-sonografia nesse processo de esclarecimento do bebê para a mãe foi destacado por Magalhães (2001) ao salientar que atualmente as informações sobre o bebê e sobre o ambiente intra-uterino são alcançadas, com alta acuidade, através deste exame. Diante de todas as possibilidades concretas de feedback sobre o bebê, o exame também apareceu nas falas das gestantes do presente estudo como meio possível para obter o esclarecimento que elas necessitavam, e nesse sentido, foi alvo de uma carga maciça de expectativas.

A ultra-sonografia aparece, nas verbalizações das gestantes, muito ligada ao seu resultado, o que pode ser explicado pelo fato de ser considerada no psiquismo dos pais, uma espécie de "teste da verdade" (Raphael-Leff, 1991) ou 
"controle/selo de qualidade" (Quayle, 1997b). Os pais sentem-se avaliados em sua capacidade procriativa de forma bastante objetiva, na medida que tudo o que deles esteve projetado no bebê é, agora, objeto de estudo (Quayle et al., 1996; 1997a). Caron (2000) discorre sobre o acerto que precisa ocorrer entre mãe, feto e placenta para que a gravidez evolua com sucesso; o que acaba, novamente, enfatizando o caráter indissociável da dupla mãe-bebê. Assim, as gestantes estavam, no momento da entrevista, prestes a receber notícias decisivas não somente sobre si e sobre o bebê em separado, mas, sobretudo sobre o andamento desta relação dual tão intensa.

É importante salientar que nestes casos a ultra-sonografia estava sendo indicada como rotina do pré-natal e já se percebe a ansiedade e a preocupação das gestantes, o que dirá em exames com indicação de suspeita ou investigação pormenorizada de diagnósticos de malformação fetal. Por isso, defende-se que o suporte psicológico na ocasião do exame de ultra-sonografia se faz muito adequada, tanto em situações de rotina como também e especialmente quando há algum problema, e pode auxiliar na qualidade da vivência da gestação e da relação com o bebê.

As gestantes referiram também preocupações quanto ao procedimento em si, revelando uma crença de que teriam um nível limitado de compreensão das imagens, além do receio diante da possibilidade de que o exame lhes causasse dor. Constata-se, especialmente na rede de saúde pública, um certo desconhecimento em relação ao exame ultra-sonográfico, no tocante a sua função e ao procedimento e esta parece ser uma das razões para estas preocupações. Esta falta de clareza em relação à ultra-sonografia pode repercutir de forma negativa nas condições do pré-natal no Brasil, uma vez que este tipo de crença, por vezes, faz com que a gestante não procure o atendimento médico para realizar exames e procedimentos necessários a sua saúde e a do bebê.

Durante e logo após o exame, os sentimentos das gestantes revelaram o impacto da ultra-sonografia sobre o seu estado emocional. Considerando que se tratam de gestantes que tiveram um resultado satisfatório no exame, percebeuse um predomínio de sentimentos positivos em suas verbalizações, envolvendo sensações de alívio e felicidade. Alguns estudos referem que esse tipo de reação é esperado principalmente pelo incremento de ansiedade que antecede o procedimento (Milne \& Rich, 1981). No caso das participantes deste estudo, percebe-se que essa satisfação não parece responder apenas ao bom resultado do exame, mas também ao fato de atender à expectativa de esclarecimentos sobre o bebê.

A intensidade da experiência vivenciada pelas gestantes durante o exame parece estar na origem dos sentimentos de emoção tão presentes nos discursos das gestantes, bem como no desencadeamento de uma espécie de "paralização" do pensamento. Isto é, devido à carga de emoção, as gestantes mostram dificuldade de explicar os sentimentos, e até relatar a experiência recém vivida, além de expressarem uma sensação de incredulidade diante das imagens do exame. Caron et al. (2000) também nos falam da sobrecarga emocional incita- da no psiquismo materno diante das imagens da ultrasonografia que apresentam o bebê à mãe de forma rápida e clara, fazendo com que as gestantes fiquem com dificuldade de explicar de forma organizada o que acabaram de experienciar. É importante salientar que esta reação tem caráter temporário e natural, em virtude da intensidade dos sentimentos vivenciados no exame.

Corroborando a literatura, a reação de várias gestantes expressou um estado de relativa confusão e extrema emoção após o exame, na medida que, na entrevista logo após o exame, não conseguiam se expressar com clareza, além de algumas terem, inclusive, manifestado reação de choro na presença da pesquisadora. Ligado a este fato, as gestantes referiram que a ultra-sonografia lhes favoreceu um desejo de externalização de emoções, tais como choro, risos e vontade de gritar. Reações desta natureza são comuns em situações em que a intensidade das emoções supera a capacidade do aparelho psíquico de absorção e controle. Assim, a ultra-sonografia parece ter propiciado uma espécie de reação de choque no psiquismo das gestantes deste estudo, completamente transitória e natural diante da intensidade da experiência, e indícios dessa reação apareceu mesmo naquelas participantes que não haviam demonstrado muitas expectativas e/ou desejos em relação ao exame.

É possível compreender que este estado emocional se deve ao nível de intensidade que parece ser inerente ao momento de ultra-sonografia. Cabe-nos compreender as razões dessa intensidade e as suas repercussões. Comecemos pelo principal recurso do qual se utiliza o exame ultrasonográfico: as imagens. As informações, mesmo que em parte sejam faladas e depois entregues em forma de laudo médico, são transmitidas, predominantemente através do visual, do estético, o que parece atingir mais diretamente o inconsciente. Seria como reduzir o caminho desse acesso, como já apontava Freud (1900/1969) no clássico estudo sobre a interpretação dos sonhos, dizendo que por estes serem constituídos basicamente por imagens, retratavam com mais fidedignidade os conteúdos do inconsciente. Tal possibilidade do exame de ultra-sonografia de ter acesso ao inconsciente também é apresentada na literatura, e nos auxilia a compreender o porquê de as gestantes poderem até, em algumas situações, expressar revivências de experiências e sentimentos do passado ${ }^{6}$ (Caron et al., 2000). As imagens do bebê e o decorrente encontro mãe-bebê pode favorecer o desencadeamento, no inconsciente, de um processo de associação ${ }^{7}$, através do qual são acessados os conteúdos psíquicos.

A intensidade dos sentimentos diante do exame ultrasonográfico se reflete, também, nas gestantes, em um desejo

\footnotetext{
${ }^{6}$ Algumas gestantes deste estudo referiram experiências anteriores que envolviam maternidade e situações difíceis de suas vidas. Estes dados estão apresentados em outro estudo dos mesmos autores, intitulado: A ultra-sonografia obstétrica e suas implicações na relação materno-fetal em situações de normalidade fetal, submetido para publicação.

${ }^{7}$ Aqui definida como qualquer ligação, consciente ou não, entre dois elementos psíquicos, cuja série constitui uma cadeia associativa (Laplanche \& Pontalis, 1967/1992, p. 36-37).
} 
de compartilhar a experiência com outras pessoas. Tratando-se de um hospital público que não permite a presença nem mesmo do pai do bebê na sala de exame, esse sentimento pode ser claramente identificado durante as entrevistas. Pode-se pensar que, além da necessidade de dividir essa carga de sentimentos, existe uma busca por, através de outrem, discriminar a fantasia da realidade. É como se encontrando "cúmplices" para o acontecido a experiência se tornasse mais real. Por vezes, esse papel foi buscado na pesquisadora através de questionamentos confirmatórios, os quais contavam com a uma resposta afirmativa desta de que o que a gestante vira havia de fato ocorrido.

No que diz respeito, especialmente, ao desejo pela presença do companheiro, Stern (1997) aponta que em virtude do amor da mãe pelo companheiro, e pela escolha dele para ser o pai do seu filho, há um desejo de oferecer-lhes o seu produto mais precioso. Além disso, o apoio emocional à gestante constitui uma importante função atribuída ao pai (Klaus \& Kennell, 1992) e, a aceitação do bebê pelo pai é um fator fundamental para o estabelecimento e para a qualidade do apego da mãe com o bebê. Pensa-se, então, que desejar a presença do companheiro no exame aponta para a necessidade da gestante de apresentar e até exibir para o pai esse produto precioso, garantindo a continuidade do seu amor e do cumprimento da paternidade. Estudos demonstraram que o acompanhamento aos exames de ultra-sonografia foi uma das formas que os pais reconheceram como mais viáveis de exercer a paternidade (Bornholdt, 2001), uma vez que, através do exame, eles puderam se sentir mais incluídos no processo gravídico já que se encontravam numa posição mais próxima à da mãe - os dois visualizam juntos e com igual alcance a imagem do bebê no monitor. Assim, mesmo para as gestantes deste estudo que não tiveram seus companheiros presentes, a ultra-sonografia foi referida como sendo uma possibilidade de lhes assegurar com mais garantia o cumprimento da paternidade e de compartilhar o sentimento de parentalidade, o que nos faz questionar a postura de alguns hospitais e/ou clínicas de não permitir a entrada no companheiro, uma vez que este parece ser um fator relevante para o bem-estar materno, para o vínculo conjugal e, por conseguinte, para a relação pais-bebê.

Um aspecto esclarecedor e organizador do exame foi expresso no discurso das gestantes quando estas relacionaram a importância do exame às funções de concretizar a gravidez e o bebê, viabilizar o contato com o bebê e informar sobre características e condições de saúde deste. Outra função referida foi a de no caso de um diagnóstico suspeito e/ ou confirmado de anormalidade, a ultra-sonografia possibilitar intervenções precoces com a dupla mãe-bebê. É como se o exame diminuísse e organizasse um pouco a confusão e as dúvidas tão excedentes no período gravídico.

Três semanas após a realização do exame ultrasonográfico, percebeu-se que algumas gestantes continuaram manifestando sentimentos positivos de felicidade/segurança e tranqüilidade, o que questiona alguns estudos que revelaram um efeito emocional do exame só de curto prazo (Hunter, Tsoi, Pearce, Chudleigh \& Campbell, 1987;
Michelacci, Fava, Grandi, Bovicelli, Orlandi \& Trombini, 1988; Stewart, 1986). Embora três semanas possa ser considerado um espaço de tempo ainda curto, acredita-se que novas pesquisas poderão mostrar que os efeitos emocionais permanecem por muito mais tempo e, por vezes, estas imagens ultra-sonográficas, marcam as pessoas por muitos anos.

Assim, passadas semanas do exame, os efeitos de "paralização" do pensamento ainda apareceram em algumas verbalizações, e foram expressos pela dificuldade de explicar os sentimentos vivenciados no exame. Acredita-se que embora o tempo transcorrido tenha contribuído para que as gestantes elaborassem melhor a experiência do exame e atenuassem essa dificuldade, não foi suficiente para que pudessem expressar com clareza a sua vivência, o que mostra o significativo grau de intensidade da experiência. Parece ser também por esta razão que as gestantes consideraram o exame, mesmo após passadas três semanas, uma experiência inesquecível.

Um outro sinal de que o impacto da vivência emocional do exame foi relativamente elaborado está nas verbalizações que referem apropriação das gestantes pelo exame, que se mostraram mais familiarizadas e exigentes em relação à próxima ultra-sonografia. O desejo de ser novamente submetida ao exame parece estar ligado a esta nova chance para utilizar outra postura, agora mais racional e crítica. Além disso, pode-se pensar que a ultra-sonografia, para algumas gestantes, esteja significando uma forma diferente das até então utilizadas para contatar e se relacionar com o bebê. Entretanto, é importante estar atento para que a ultrasonografia não seja vista como a única forma dessa relação e sim como uma oportunidade complementar e/ou diferenciada de contato. Apesar de ser possível observar que as gestantes, após a realização do exame passaram a considerá-lo uma forma bastante diferenciada de contato, não se pode afirmar que as demais foram subjugadas.

A ultra-sonografia foi percebida pelas gestantes, depois de três semanas, como tendo servido de estímulo para que elas imaginassem/pensassem mais sobre o bebê. Zlotogorsky, Tadmor, Rabinowitz e Diamant (1997) reportaram que as imagens do bebê no exame de ultra-sonografia influenciaram profundamente no aumento de fantasias e idealizações das gestantes sobre o bebê, o que também apareceu nos achados deste estudo. O exame parece servir então como um elemento que personifica, dá um corpo ao bebê na mente da mãe, possibilitando que ela o imagine mais, e interaja mais com ele, pelo menos em pensamento. Assim, as concepções de que o exame, por trazer uma realidade muito precocemente, interromperia as fantasias da mãe em relação ao bebê (Courvoisier, 1985; Soulé, 1987) não parece receber apoio nas falas das gestantes do presente estudo.

As gestantes continuaram referindo que a importância do exame estava no fato de lhes proporcionar um sentimento de concretização da gravidez e do bebê, e de possibilidade de conhecer o bebê antes do nascimento, o que novamente parece resultado de um processo de elaboração. O intervalo de três semanas, neste caso, pareceu ter, então, servido para reforçar a idéia de concretização vivida no dia do exame. 
A preparação emocional que a ultra-sonografia possibilita em casos de diagnósticos indesejados foi expressa pelas gestantes como função importante, o que corrobora a literatura que acredita que a precocidade na comunicação de um diagnóstico de anormalidade reserva aos pais um maior espaço de tempo para terem uma maior clareza psíquica e prática sobre a realidade (Kroeff, Maia \& Lima, 2000; Quayle et al., 1996). No entanto, pode-se pensar que estas participantes verbalizaram tal idéia por terem tido seus resultados satisfatórios, o que não nos possibilita dizer que as gestantes, em geral, realmente desejem saber precocemente sobre resultados indesejados.

Pode-se inferir que a experiência da ultra-sonografia teve um importante impacto emocional para as gestantes, mesmo antes da sua realização, trazendo implicações para as gestantes e para a sua relação com o bebê. Hyde (1986) estudou as atitudes das gestantes em relação a este exame e constatou que, independente de suas condições, o uso do diagnóstico ultra-sonográfico que mostra o bebê no útero da mãe é sempre muito significativo, tanto do ponto de vista social como psicológico. Assim, o exame não é passível de ser considerado com indiferença pelos profissionais que direta ou indiretamente estão ligados a esta área, exigindo uma postura de cautela e sensibilidade para lidar com as situações que envolvem o contex to de ultra-sonografia mesmo diante de resultados de normalidade fetal.

\section{Considerações Finais}

Examinando as impressões e sentimentos das gestantes a respeito da ultra-sonografia, percebe-se uma idéia quase constante de ter se tratado de uma experiência bastante intensa e diferenciada. Independente das particularidades de cada vivência é possível perceber que, de maneira geral, o exame tende a impactar psiquicamente as gestantes e a idéia que elas constroem a respeito de seus bebês. Dessa forma, parece ser um momento notório no transcorrer do período gravídico, merecendo atenção e cuidado dos familiares e, especialmente, dos profissionais de saúde envolvidos com o procedimento.

Assim, vale enfatizar que diante da massificação e da necessidade da ultra-sonografia como importante recurso do pré-natal, não é nosso objetivo questionar a realização deste exame, mas cabe a nós, profissionais da saúde, atentar para o fato de que este exame acarreta implicações emocionais em qualquer gestante que o realiza. Assim, qualquer profissional que lida com esta área e com a situação de exame ultra-sonográfico deve ser habilitado a proferir um ambiente de qualidade, não somente técnica, mas também emocional.

Um ponto importante a ser ressaltado diz respeito à presença do companheiro ou de alguma outra pessoa junto à gestante durante a realização do exame. Estudos salientaram que o vínculo conjugal aumentou depois de exames nos quais o companheiro pode estar presente e que a participação no exame foi vista por alguns pais como uma das formas mais ativas e importantes para o sentimento de paternidade. Assim, é importante se questionar a proibição da entrada de acompanhantes, e especialmente, dos pais durante a realização do exame ultra-sonográfico, que ocorre em algumas clínicas e hospitais. Sabe-se que essa postura impera na maioria dos hospitais públicos e que isso se deve ao elevado número de pacientes para serem atendidas, requerendo maior agilidade no procedimento, além do reduzido espaço físico onde são realizados os exames. Porém, diante das evidências do presente estudo e de outros relatados na literatura e compreendendo a importância emocional da ultra-sonografia para as gestantes, para os pais, para o casal, para os familiares, e conseqüentemente, para o bebê, sugere-se que esta postura seja revista nos locais de exames pré-natais. Isto teria repercussões muito positivas para todos os envolvidos, especialmente para a relação mãe-paibebê, presente e futura, sem custo financeiro maior.

Por fim, é mister enfatizar que as consultas do pré-natal e especialmente a situação de ultra-sonografia constituem, muitas vezes, os únicos momentos em que as mulheres são vistas por profissionais da saúde durante a gestação. Desse modo, o exame se constitui em um importante momento para as vidas de mães e bebês, com implicações emocionais para ambos e para a relação atual e futura da díade, após o nascimento do bebe. Este momento do exame, passa a ser, então, uma via de contato com o bebê e a gestante, não somente com o intuito de detectar eventuais problemas, mas pode também ser utilizado preventivamente para identificar e fornecer eventual suporte emocional para as mães que o necessitem.

\section{Referências}

Baillie, C., Mason, G., \& Hewison, J. (1997). Scanning for pleasure. British Journal of Obstetrics and Gynaecology, 104, 1123-1124.

Bornholdt, E. (2001). A gravidez do primeiro filho à luz da perspectiva paterna. Dissertação de Mestrado não-publicada, Instituto de Psicologia, Pontifícia Universidade Católica do Rio Grande do Sul, Porto Alegre, RS.

Caccia, N., Johnson, J., Robinson, G., \& Barna, T. (1991). Impact of prenatal testing on maternal-fetal bonding: Chorionic villus sampling versus amniocentesis. American Journal Obstetric Gynecology, 4, 1122-1125.

Caron, N. (2000). O ambiente intra-uterino e a relação maternofetal. In N. Caron (Ed.), A relação pais-bebê: Da observação à clínica (pp. 119-134). São Paulo, SP: Casa do Psicólogo.

Caron, N., Fonseca, M., \& Kompinsky, E. (2000). Aplicação da observação na ultra-sonografia obstétrica. In N. Caron (Ed.), A relação pais-bebê: Da observação à clínica (pp. 178-206). São Paulo, SP: Casa do Psicólogo.

Courvoisier, A. (1985). Échographie obstétricale et fantasmas. Neuropsychiatrie de Lénfance Enfant, 33, 103-105.

Fletcher, J., \& Evans, M. (1983). Maternal bonding in early fetal ultrasound examinations. New England Journal of Medicine, 308, 392-393.

Fonseca, M., Magalhães, J., Papich, H., Dias, R., \& Schimidt, A. (2000). Ultra-sonografia em obstetrícia: Explorando um novo mundo. In N. Caron (Ed.), A relação pais-bebê: Da observação à clínica (pp. 97-118). Porto Alegre, RS: Casa do Psicólogo.

Freud, S. (1969). A interpretação dos sonhos (M. A. M. Rego, Trad.). In J. Salomão (Ed.), Edição standard brasileira de obras completas de Sigmund Freud: Vol. 4. Rio de Janeiro, RJ: Imago. (Original publicado em 1900). 
Garrett, C., \& Carlton, C. (s.d.). Difficult decisions in prenatal diagnosis. In L. Abamsky \& J. Chapple (Eds.), Prenatal diagnosis: The human side (pp. 86-105). London: Chapman \& Hall.

Grebedenik, E. (1990). Calming or Harming? A critical review of psychological effect of fetal diagnosis on pregnant women. Galton Institute - Occasional Papers Second Series, 2, 19.

Grupo de Interação Social, Desenvolvimento e Psicopatologia. (1998a). Consentimento livre e esclarecido. Porto Alegre, RS: Universidade Federal do Rio Grande do Sul, Instituto de Psicologia. Manuscrito não publicado.

Grupo de Interação Social, Desenvolvimento e Psicopatologia. (1998b). Ficha de dados demográficos da gestante. Porto Alegre, RS: Universidade Federal do Rio Grande do Sul, Instituto de Psicologia. Manuscrito não publicado.

Heidrich, S., \& Cranley, M. (1989). Effect of fetal movement, ultrasound scans, and amniocentesis on maternal-fetal attachment. Nursing Research, 38, 81-84.

Hunter, M., Tsoi, M., Pearce, M., Chudleigh, P., \& Campbell, D. (1987). Ultrasound scanning in womwn with raised alpha fetprotein: Long-term psychological effects. Journal of Psychosomatic Obstetrics Gynaecology, 6, 25-31.

Hyde, B. (1986). An interview study of pregnant women's attitudes to ultrasound scanning. Society Science Medicine, 22, 587-592.

Isfer, E. (1997). Medicina fetal: O feto, o paciente. In J. Wilheim (Ed.), Decifrando a linguagem dos bebês. Anais do Segundo Encontro Brasileiro para o Estudo do Psiquismo Pré e Peri Natal (pp. 181-192). São Paulo, SP: Cop L Print.

Kemp, V., \& Page, C. (1987). Maternal prenatal attachment in normal and high-risk pregnancies. Journal of Obstetric Gynecology and Neonatal Nursing, 16, 179-184.

Klaus, M., \& Kennel, J. (1992). Pais/bebê: A formação do apego. Porto Alegre, RS: Artes Médicas.

Kohn, C., Nelson, A., \& Weiner, S. (1980). Gravida's response to realtime ultrasound fetal image. Journal of Obstetric, Gynecology and Neonatal Nursing, 9, 77-80.

Kroeff, C., Maia, C., \& Lima, C. (2000). O luto do filho malformado. Femina, 28, 395-396.

Laplanche, J., \& Pontalis, J.-B. (1992). Vocabulário de Psicanálise. São Paulo, SP: Martins Fontes. (Original publicado em 1967)

Laville, C., \& Dionne, J. (1999). A construção do saber: Manual de Metodologia da Pesquisa em Ciências Humanas. Porto Alegre, RS: Artes Médicas.

Magalhães, J. (2001). Medicina fetal. In F. Freitas, S. MartinsCosta, J. Ramos \& J. Magalhães (Eds.), Rotinas em obstetrícia (pp. 38-47). Porto Alegre, RS: Artes Médicas.

Michelacci, L., Fava, G., Grandi, S., Bovicelli, L., Orlandi, C., \& Trombini, G. (1988). Psychological reactions to ultrasound examination during pregnancy. Psychoterapy Psychossomatic. 50, 1-4.
Milne, L., \& Rich, U. (1981). Cognitive and affective aspects of the responses of pregnant women to sonography. Maternal Child Nursing Journal, 10, 15-39.

Piontelli, A. (2000). Is there something wrong? The impact of technology in pregnancy. In J. Raphael-Leff (Ed.), 'Spilt milk' perinatal loss \&̊ Breakdown (pp. 39-52). London: Institute of Psychoanalysis.

Quayle, J. (1997a). Óbito fetal e anomalias fetais: Repercussões emocionais maternas. In M. Zugaib, J. Tedesco \& J. Quayle (Eds.), Obstetrícia psicossomática (pp. 216-227). São Paulo, SP: Atheneu.

Quayle, J. (1997b). Parentalidade e Medicina Fetal: Repercussões emocionais. In M. Zugaib, M. Brizot, V. Bunduki \& D. Pedreira. Medicina Fetal. São Paulo, SP: Atheneu.

Quayle, J., Isfer, E., \& Zugaib, M. (1991). Considerações acerca das representações associadas ao diagnóstico pré-natal. Revista de Ginecologia e Obstetrícia, 2, 34-38.

Quayle, J., Neder, M., Mihaydaira, S., \& Zugaib, M. (1996). Repercussões na família do diagnóstico de malformações fetais: Algumas reflexões. Revista de Ginecologia e Obstetrícia, 7, 1, 33-39.

Ramona-Thieme, M. (1995). Becoming a mother: Research on maternal identity from Rubin to the present. New York: Spring.

Raphael-Leff, J. (1991). Psychological processes of childbearing. London: Chapman \& Hall.

Raphael-Leff, J. (1997). Gravidez: A história interior (R. D. Pereira, Trad.). Porto Alegre, RS: Artes Médicas.

Sioda, T. (1984). Psychological effects of cardiotocographic and ultrasonographic examinations in pregnancy and labour on the mother. Ginekologia Polska. 55, 653-660.

Soulé, M. (1987). O filho da cabeça, o filho imaginário. In T. Brazelton, B. Cramer, L. Kreisler, R. Schappi \& M. Soulé (Eds.), A dinâmica do bebê (pp. 132-170). Porto Alegre, RS: Artes Médicas.

Stake, R. (1994). Case studies. In N. Denzin \& Y. Lincoln (Eds.), Handbook of qualitative research (pp. 236-247). London: Sage.

Stainton, M. C. (1985). The fetus: A growing member of the family. Family Relations, 34, 321-326.

Stern, D. (1997). A constelação da maternidade: O panorama da psicoterapia pais/bebê. (M. A. V. Veronese, Trad.). Porto Alegre, RS: Artes Médicas.

Stewart, N. (1986). Women's views of ultrasonography in obstetrics. Birth, 13, 1, 39-43.

Zlotogorsky, Z., Tadmor, O., Rabinowitz, R., \& Diamant, Y. (1997). Parental attitudes toward obstetric ultrasound examination. Journal of Obstetric Gynaecology, 23, 25-28.

Recebido: 23/11/2005

$1^{a}$ revisão: 31/05/2006

Aceite final: 19/07/2006 